\title{
Drug Delivery Development: Quality Concepts, Challenges and Prospects
}

\author{
Surendra Agrawal* \\ Department of Pharmacy, Shobhaben Pratapbhai Patel School of Pharmacy \& Technology Management, India
}

Submission: August 28, 2017; Published: September 14, 2017

*Corresponding author: Surendra Agrawal, Department of Pharmacy, Shobhaben Pratapbhai Patel School of Pharmacy \& Technology Management, SVKM's NMIMS, Vile Parle (W), Mumbai 400056, India, Email: surendra.agrawal@nmims.edu

\section{Abstract}

Quality, being a key to success in competitive market is an imperative indicator of product. It is important to recognize that quality cannot be tested into products, i.e., quality should be built in by design. The search for new drug delivery approaches and new modes of action is a rapidly developing field. Modes of drug delivery have changed in the past few decades and the future looks set to provide even more therapeutic advances. DDS can be developed to target common and rare diseases; both come with their challenges and opportunities, which are explored in this article.

Challenges in quality drug development mainly includes negligence from management, material management, quality personnel, lack of validated process, lack of equipment qualification, improper documentation, research validation specially related to novel drug delivery system. Nevertheless these challenges can be reduced to an appreciable level with the proper training, initiatives from management, continuous validation programmes and accepting novel drug delivery development considering risk assessment.

Keywords: NDDD; Quality issues in NDDD; Drug development challenges

\section{Introduction}

The quality in the pharmaceutical industry has become a major concern and there has been a growing awareness for the significance of the quality of the pharmaceutical products. The current concept of Good Manufacturing Practices (GMP) accentuates that the quality of pharmaceutical products must be constructed during the overall process cycle [1]. Quality is never improved in a common way. It is always improved project by project, beginning with the most significant problems [2]. The deficiency to be challenged must be clearly specified \& the expected improvement can be defined in measurable terms [3]. This article examines the current status of quality related issues in development of drug delivery system with the objectives of assessing challenges and prospects.

\section{Challenges}

Challenging molecules and challenging markets is the key factor in drug development process. "On the molecule side, the pipeline is full of molecules with bioavailability, stability, targeted delivery, controlled release, and manufacturability challenges $[4,5]$. The benefit to risk ratio seems far removed and in true sense there is a functional gap between the development function and technical operations in the drug companies [6]. Cost of quality involves prevention cost, appraisal cost, internal failure cost (Scrap, rework and material losses) and external failure cost (returns and recalls), which has been neglected in the development process of delivery systems [7]. Global regulatory trends are yet to be defined fully, despite the several attempts already performed specially for novel drug delivery systems like Nano medicines. The other crucial issue is scale up. Commercial manufacturing uses much larger quantities compared to supply for the laboratory-scale experiments and, therefore, is a different ball game. Raw material batch-to-batch variability needs to be understood, process capabilities evaluated, and controls demonstrated by the vendor [8-10].

\section{Prospects}

The physicochemical and biological properties of the drug substance that can influence the performance of the drug product and its manufacturability should be identified and discussed [11]. The information on excipient performance can be used, as appropriate, to justify the choice and quality attributes of the excipient and to support the justification of the drug product specification [12]. Supportive management (philosophically and financially) can bring a quality concept and develop quality culture in the employees [13]. Quality policies need to be adopted indicating the goals of organization and support system in place 
to achieve those goals. Responsive deviation and investigation systems that lead to timely remediation will reduce the batch to batch variations [14].

Well-defined, designed and validated processes during entire product development life cycle can assure the product quality and reproducibility. While the rules and guidelines are quite well in place, there exists a non-uniform interpretation of these rules. An emphasis on the training of continuous manufacturing technologies, regulatory and organizational approaches is the need of hour in development of novel drug delivery system [13]. Fostering voluntary compliance by the researcher should be the focus rather than adopting more strict regulations [14]. A full scale design of experiment (Quality by Design) that begins with predefined objectives should be considered in the developmental strategy. It highlights product and process understanding and process control, based on Science-based approaches and sound methods for assessing risk [8]. This systematic approach can enhance achieving the desired quality of the product and helps in understanding manufacturing strategy. Process development studies should provide the basis for process improvement, process validation, continuous process verification (where applicable), and any process control requirements as given in Figure 1 [15].

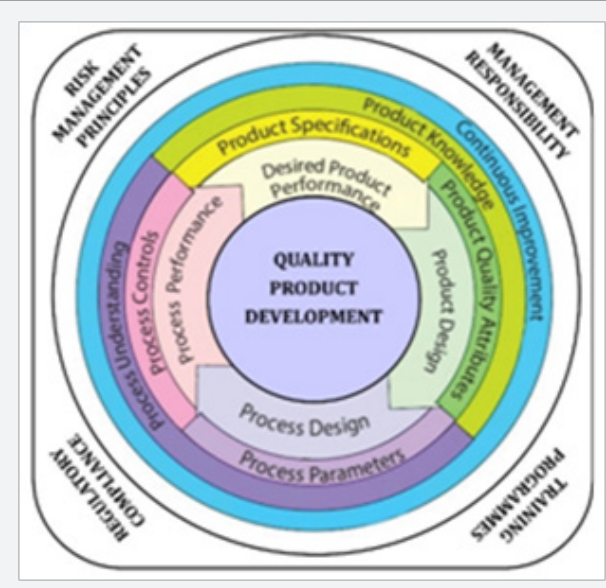

Figure 1: Principles of Quality product development

\section{Discussion}

A systematic process plan and plant design undertaken by management and its implementation by considering trainings and research validation as part of the program can definitely lead to a quality product. QbD is just an approach to design a robust product but a quality product can be achieved only with the agreement of ethical principles for voluntary compliance rather than just fulfilling regulatory and organizational goals.

\section{Conclusion}

Quality drug development is not a rocket science but it's just willingness of researchers involving certain principles to be followed.

\section{References}

1. WHO (1992) Good Manufacturing Practices for pharmaceutical products. In: WHO Expert Committee on Specifications for Pharmaceutical Preparations, Thirty-second report. World Health Organization, Geneva, Switzerland.

2. Melsa JL (1999) Total Quality Management. In: Sage AP, Rouse WB (Eds.), Handbook of Systems Engineering and Management. John Wiley and Sons, New York, USA.

3. Challener C (2016) New Drug-Delivery Methods: From Concept to Patient accessed on $23^{\text {rd }}$ August 2017.

4. Basu PK (2010) Improving Pharmaceutical Product Development and Manufacturing: Impact on cost of drug development and Cost of Goods Sold for pharmaceuticals. In: World Drug Manufacturing Summit. Berlin, Germany.

5. Brown SL, Eisenhardt KM (1995) Product development: past research, present findings, and future directions. Academy of management review 20(2): 343-378.

6. Wong C, Rafa (2011) Using Operational Excellence to Meet the New Process Validation Guidance. Pharmaceutical Engineering.

7. Wechsler J (2017) Efficient Manufacturing Critical for Accelerated Drug Development. Bio Pharm International 30(6): 8-9.

8. Gupta A, Fuloria KN (2012) Short review on Quality by design: A new Era of Pharmaceutical drug development. International Journal of Drug Development \& Research 4 (3): 19-26.

9. Barnett B, Clark K (1996) Technological newness: an empirical study in the process industries. Journal of Engineering and Technology Management 13(3-4): 263-282.

10. Guidance for Industry (2001) Process Validation: General Principles and Practices, US Department of Health and Human Services Food and Drug Administration, CDER, CBER, CVM, Current Good Manufacturing Practices (CGMP), Rev 1.

11. Rathore A, Kateja N, Agarwal H, Sharma AK (2016) Continuous Processing for the Production of Biopharmaceuticals. Biopharm International 29(4): 14-19.

12. Doll WJ, Hong P, Nahm A (2010) Antecedents and outcomes of manufacturability in integrated product development. International Journal of Operations \& Production Management 30(8): 821-852.

13. Uydess I, Meyers C (2011) Developing and Sustaining a Quality Culture. Bio Pharm Intl 24: 20-22.

14. Kusunoki K, Nonaka I, Nagata A (1998) Organizational capabilities in product development of Japanese firms: a conceptual framework and empirical findings. Organization Science 9(6): 699-718.

15. Patravale VB, Disouza John I, Rustomjee M (2016) Pharmaceutical product development: Insights into pharmaceutical processes, management and regulatory affairs, CRC Press, USA. 
This work is licensed under Creative

Commons Attribution 4.0 License

DOI: $10.19080 /$ NAPDD.2017.02.555593
Your next submission with Juniper Publishers will reach you the below assets

- Quality Editorial service

- Swift Peer Review

- Reprints availability

- E-prints Service

- Manuscript Podcast for convenient understanding

- Global attainment for your research

- Manuscript accessibility in different formats

( Pdf, E-pub, Full Text, Audio)

- Unceasing customer service

Track the below URL for one-step submission https://juniperpublishers.com/online-submission.php 